\title{
Responsabilidade socioambiental corporativa: um estudo de caso na Caixa Econômica Federal
}

Danielle Duailibe Zanchetta'

\section{Resumo}

O aumento da consciência ambiental consolidou a Responsabilidade Socioambiental Empresarial no setor bancário brasileiro. Os principais bancos públicos e privados do país passaram a compreender que é possível ser sustentável e gerar lucro. A comunicação interna, nesse caso, exerce papel fundamental na divulgação do papel social, ambiental e econômico dessas instituições para que novos valores sejam incorporados e consolidados por seus funcionários e, posteriormente, cheguem a seus clientes. Estudar os valores corporativos da Caixa Econômica Federal e pesquisar as ferramentas de comunicação utilizadas por essa instituição foi fundamental para identificar e compreender as dificuldades enfrentadas por um banco público no desenvolvimento de um endomarketing que sensibilize seus funcionários para a prática da sustentabilidade dentro e fora da empresa. Ter consciência e atitude socioambiental depende do enraizamento de novos valores na cultura corporativa dessa instituição.

Palavras-chave: Cultura corporativa. Banco público. Endomarketing. Responsabilidade socioambiental. Setor bancário brasileiro.

\section{Introdução}

O superaquecimento da Terra é um assunto que está em pauta desde a década de 60. As mudanças climáticas globais têm impacto diretamente na biodiversidade,

1 Especialista em gestão da comunicação nas organizações pelo Centro Universitário de Brasília (UniCEUB); Graduada em co municação social pela Universidade Católica (UCB); Coordenadora da assessoria de comunicação do Ministério da Fazenda. E- mail: daduzan@gmail.com 
assim como na vida humana e no desenvolvimento da economia mundial. Nos últimos anos, o Brasil vem apresentando estabilidade econômica, o que gera aumento do poder de crédito da população. $\mathrm{O}$ resultado não é positivo. $\mathrm{O}$ uso errado do dinheiro potencializa a produção de combustíveis fósseis, causando maior emissão de gases de efeito estufa (GEEs).

Para Becker (1997), o grande desafio da sustentabilidade é desenvolver métodos no sistema de produção que obedeçam a três preceitos fundamentais: igualdade social, prudência ecológica e eficácia econômica.

Boff (1999) defende que cada pessoa precisa sentir-se parte do ecossistema e da comunidade biótica, e que é necessário haver um processo coletivo de educação para que toda a sociedade seja sustentável. A partir do momento que as pessoas entenderem que a sustentabilidade está entre o que se poupa e o que se desperdiça, as práticas individuais e coletivas causarão mais mudanças de comportamento.

A Declaração das Responsabilidades Humanas para a Paz e o Desenvolvimento Sustentável da Organização das Nações Unidas, considerado um marco institucional no debate da responsabilidade socioambiental, diz que é possível ter lucratividade e ser sustentável; ter responsabilidade socioambiental aplicada aos negócios e continuar crescendo economicamente.

Com uma nova forma de pensar e atuar, muitas empresas já mostram mudanças de comportamento em busca de alternativas para minimizar os impactos do aquecimento global. No setor bancário não é diferente.

Tendência ou não, a era da consciência ambiental também fisgou os bancos no Brasil. Esse novo comportamento criou novos parâmetros na escolha de como e em quem as instituições financeiras querem investir o seu capital. O resultado está nas políticas de crédito adotadas, nas quais pessoas físicas e jurídicas, cujos nomes constem em listas de órgãos oficiais por infringirem leis ambientais, não têm mais acesso facilitado ao crédito. 
Mas os bancos ainda precisam identificar o melhor caminho para atender às suas necessidades $\mathrm{e}$ a de seus clientes, protegendo o capital humano, mantendo o natural e melhorando o financeiro, para as gerações futuras. O caminho não é fácil. Algumas instituições financeiras, principalmente as públicas, enfrentam dificuldades para aliar o discurso socioambiental à sua prática e, assim, manter padrões sustentáveis em suas estruturas organizacionais. A Caixa Econômica Federal é uma delas.

Com vistas a contribuir com o setor bancário brasileiro, apontando os problemas que um banco público enfrenta na implantação de ações de responsabilidade social e ambiental dentro e fora da empresa, o objetivo deste trabalho é estudar a CAIXA para compreender seus valores corporativos, conhecer suas ações de responsabilidade socioambiental e estudar as dificuldades de seu endomarketing, para entender como essa instituição financeira utiliza os canais de informação para se comunicar com seus funcionários de forma eficiente.

Para construir o embasamento deste estudo de caso, destaca-se uma discussão da importância da prática socioambiental pelas empresas no Brasil. Em complemento, é importante explicar o significado e o papel dos stakeholders dentro deste tema. Apresenta-se também uma pesquisa sobre a sustentabilidade dos bancos no Brasil. Este estudo conceitua o endomarketing e analisa a influência da cultura organizacional na comunicação interna da empresa. O estudo de caso começa com a descrição das principais características da CAIXA e as formas de consumo sustentável presentes na instituição. Destacam-se ainda as ferramentas utilizadas para desenvolver a comunicação interna do banco. Por fim, apresenta-se o processo de coleta de dados e a análise de conteúdo das entrevistas, assim como os resultados do estudo de caso e o referencial teórico.

\section{A responsabilidade socioambiental empresarial no Brasil}

A preocupação com a pobreza, o desperdício, a degradação ambiental, a decadência urbana, o crescimento populacional, os direitos humanos e a saúde fizeram surgir uma nova relação entre as empresas, os governos e a sociedade. A 
partir dessa nova consciência, os empresários identificaram no desenvolvimento sustentável a solução para continuarem ganhando espaço no mercado, sem perderem a lucratividade.

Almeida (2002, p. 65) defende que "no mundo sustentável, uma atividade - a econômica, por exemplo - não pode ser pensada ou praticada em separado, porque tudo está inter-relacionado, em permanente diálogo”.

Um aspecto abordado por Henderson (2003, p. 21) explica que “os padrões de sustentabilidade devem incluir a extensão das interações humanas com soma diferente de zero, ou seja, os jogos ganha-ganha e a evolução da cooperação humana”. Para ela, a competição e a cooperação são de extrema importância para o desenvolvimento de uma sociedade. No entanto, seus efeitos devem priorizar a preservação ambiental.

A solução para mitigar os efeitos do aquecimento global não está em escolher entre o crescimento econômico e a qualidade do meio ambiente, mas em criar fatores que harmonizem as esferas socioeconômicas e ambientais, como defende Becker (1997).

Para tornar isso possível, as dimensões da sustentabilidade devem ser aplicadas por meio de três pilares interdependentes e mutuamente sustentadores. O conhecido tripé da sustentabilidade (triple bottomline) é defendido por Merico (2002) como a essência para o desenvolvimento econômico, social e de proteção ambiental.

Seguir o caminho da sustentabilidade empresarial é uma escolha inteligente que muitas empresas têm feito, assim como aplicar a base do tripé em suas decisões. Sabe-se que a transparência na gestão dos negócios e a conduta ética da empresa agregam valores positivos à imagem da organização, consolidando a marca junto aos consumidores, clientes, investidores e acionistas.

Bicalho et al (2003, p. 6) acreditam que "diante dos novos desafios colocados às empresas, a imagem institucional passa a ser um dos diferenciais decisivos em relação à concorrência”. 
Essa consciência socioambiental mostra que os mercados terão como expoentes as empresas e marcas que agregarem valores morais e éticos a seus produtos, com o objetivo de tornarem-se agentes transformadores em seu campo de atuação. Felix (2004) lembra que as empresas têm buscado aumentar sua competitividade agregando o valor da Responsabilidade Socioambiental Empresarial - RSE - às suas marcas.

Um exemplo da crescente discussão em torno da questão da RSE é a pesquisa "Responsabilidade Social das Empresas: percepção do consumidor brasileiro - 2006/2007", resultado de um trabalho do Instituto Akatu pelo Consumo Consciente e do Instituto Ethos. O estudo mostra a percepção de 800 consumidores brasileiros diante dessa questão por parte das empresas.

A pesquisa concluiu que o consumidor brasileiro sabe o significado de RSE e associa as empresas a um papel social. Por outro lado, o documento apontou que o consumidor não sabe diferenciar se as empresas realizam ações de RSE para melhorar sua imagem, ou se estão realmente engajadas nessa prática.

\subsection{O papel dos stakeholders}

Durante o estudo do conceito de RSE, é comum ler a palavra stakeholder. O significado dessa palavra está diretamente ligado às relações de interdependência que são marcadas por influências recíprocas, ou seja, pessoas que podem afetar ou serem afetadas pelas ações de uma organização. O stakeholder de uma empresa pode ser um empregado, um fornecedor, um cliente, um governo, um acionista e um consumidor.

Para Martins (2001), também se pode classificar como stakeholders a imprensa, as organizações de proteção ambiental estatais e não estatais, os organismos internacionais, as instituições creditícias e as entidades religiosas. Martins (2001, p.2) salienta que "as influências mútuas nas relações stakeholder-empresa vão atuar direta ou indiretamente na escolha da estratégia a ser implementada na tomada de decisão organizacional”. 
Martins (2001) afirma que os empregados são os stakeholders do ambiente interno das empresas que influenciam o custo do produto ou serviço oferecido pela organização.

Conclui-se então que os stakeholders atuam de forma direta e indireta, melhorando os produtos e serviços oferecidos pelas empresas e, consequentemente, fazendo com que elas superem seus resultados. A partir dessa ação, vale destacar que os stakeholders que mais influenciam o desempenho das empresas são: empregados, acionistas, clientes e fornecedores.

Os clientes, para Campbell (apud MARTINS, 2001, p. 8), são stakeholders "externos ligados ou afetados pelo processo decisório das empresas, visto que sobre eles fundamentam-se as estratégias de desenvolvimento do negócio”.

Para Almeida (2002, p. 82), “informar é dar aos stakeholders, sobretudo ao consumidor, a oportunidade de escolha”. Nessa relação, nota-se que informar é também criar uma relação de confiança entre a empresa e o consumidor.

\section{A responsabilidade socioambiental dos bancos no Brasil}

O setor bancário brasileiro nasceu antes da declaração da Independência do Brasil, com a criação do Banco do Brasil no ano de 1808. A partir do século XX, as instituições financeiras de hoje começaram a surgir, atuando como pequenos bancos regionais.

Na década de 60, o sistema financeiro passou por uma reforma. A reestruturação foi feita por meio da Lei da Reforma Bancária (Lei nº . 4595), instituída em 31 de dezembro de 1964, com a criação do Banco Central e do Conselho Monetário Nacional.

Essa reforma resultou na concentração e aumento do volume de ativos, no crescimento econômico, no aumento das taxas de juros, na alta da inflação e no desenvolvimento de tecnologia bancária. 
No início dos anos 90, o Banco Central publicou uma resolução, permitindo a criação de bancos múltiplos. Esse passo foi importante para estimular a abertura de novas instituições no Brasil e gerar competição nos serviços ofertados.

Informações do Relatório Social de 2006 da Federação Brasileira de Bancos -Febraban - relatam que o Brasil possuía 159 instituições financeiras, operando até dezembro de 2006. De acordo com o Banco Central do Brasil, os ativos do sistema bancário somavam $\mathrm{R}$ 1,76 trilhão e o patrimônio líquido das instituições era de R\$ 164,7 bilhões no mesmo período.

Segundo o mesmo relatório, o crescimento econômico foi 3,7\% superior ao registrado em 2005 (2,9\%). Esse desenvolvimento da economia refletiu diretamente nos investimentos socioambientais das empresas.

O documento mostra que, em 2006, há um incremento de 33\% no número de instituições que realizaram auditorias relacionadas às suas práticas ambientais. $\mathrm{O}$ ano anterior havia registrado $10 \%$.

O relatório ainda divulgou que, dos principais bancos públicos e privados pesquisados, $50 \%$ mantinham profissionais especializados em risco e oportunidades ambientais. No mesmo ano, os bancos brasileiros investiram R $\$ 63,5$ milhões em programas e projetos de melhoria ambiental.

Na busca pela sustentabilidade empresarial, o Instituto de Defesa do Consumidor (IDEC), realizou pesquisa sobre o discurso e a conduta dos principais bancos brasileiros entre os meses de maio e dezembro de 2007.

O objetivo da pesquisa era oferecer ao consumidor final a opção de comparar as ações com os discursos das empresas. A escolha do setor bancário se deu pelo impacto que os bancos têm na economia, assim como a influência que o setor financeiro impõe sobre o comportamento das empresas.

Para participar da pesquisa, os bancos precisavam ter mais de um milhão de clientes pessoa física. O instituto também excluiu os bancos estaduais e os que 
apresentavam carteira comercial restrita. As instituições selecionadas foram as seguintes: Real ABN Amro Bank, Bradesco, Banco do Brasil, Caixa Econômica Federal, HSBC, Itaú, Santander e Unibanco.

A partir dessa pesquisa, o IDEC (2008, p. 64) identificou que os bancos precisam aperfeiçoar muito suas práticas de responsabilidade socioambiental, inclusive no que se refere ao consumidor. O documento também mostra que há diferenças entre as instituições na postura e na prática de RSE.

Concluiu-se, então, com base na avaliação apresentada pelo IDEC, que a responsabilidade socioambiental dos bancos brasileiros está mais concentrada na publicidade e marketing do que nas ações das instituições.

\subsection{A importância do endomarketing}

Com a alta competitividade e o aumento do aquecimento global, as empresas precisam mostrar para os stakeholders sua estrutura, missão, visão e ações. No entanto, para que a comunicação externa de uma empresa atinja seu público-alvo, é necessário que antes haja uma comunicação interna sólida e efetiva, na qual a empresa informa para seus funcionários em primeira mão todas as estratégias e ações da organização.

Para Bekin (1995, p. 7), o endomarketing contribui "decisivamente para a formação de um ambiente empresarial favorável ao conhecimento e aos valores compartilhados por todos que compõem uma empresa do topo à linha de frente”.

Nesse sentido, é primordial que a empresa promova a integração dos setores, valorizando os funcionários, incentivando-os a se comprometerem com os valores da organização.

Kempenich (1997, p. 72) defende que o funcionário é o grande parceiro do negócio. O que Kempenich quer dizer é que o empregado tem que se envolver em todo o processo para que o negócio tenha sucesso. 
Grönroos (1993) acredita que os dois objetivos do endomarketing são atrair e reter bons funcionários, e assegurar que os empregados se motivem a uma orientação ao cliente e a um desempenho consistente dos serviços. $\mathrm{O}$ autor conclui que um endomarketing bem sucedido deve integrar a gestão estratégica da empresa. O processo não deve ser impedido por qualquer estrutura organizacional, e a alta gerência tem que apoiar constantemente o endomarketing.

Por fim, Silva (2007, p. 3) completa que a comunicação tem que ser de dentro para fora. "Não basta apenas definir como comunicar essa imagem, mas sim como ter dentro da empresa, entre todos os seus funcionários, atitudes que reflitam o seu modo de ser, os seus valores, sua forma de atuar nos negócios”.

\subsection{Cultura organizacional na comunicação da empresa}

A cultura organizacional é um conceito em desenvolvimento no Brasil. Com base na restrita bibliografia com abordagem do mercado brasileiro, conclui-se que a cultura organizacional pode atrapalhar o desenvolvimento da comunicação de uma empresa.

Em termos gerais, a cultura empresarial é sustentada pelas empresas a partir de um conjunto de normas e ideias. A criação dessas regras torna fácil o convívio das pessoas.

Grönroons (1997, p. 304) acredita que a cultura empresarial pode afetar e alterar o clima interno da organização. Nesse sentido, o autor define a cultura empresarial como:

[...] um conjunto de normas e valores mais ou menos comuns compartilhado pelas pessoas da organização. Portanto, a cultura é um conceito geral que explica porque as pessoas fazem certas coisas, pensam de uma certa maneira comum e apreciam metas, rotinas e até situações similares, só porque pertencem a uma mesma organização. 
Grönroons (1997) defende ainda que "uma cultura corporativa fraca, na qual haja poucos, ou nenhum valores e normas comuns, cria um sentimento de insegurança com relação a como responder e reagir a várias situações diferentes". A partir dessa linha de pensamento, conclui-se que uma cultura forte permite que a postura e as respostas dos funcionários sejam uniformes.

Ao contrário de Grönroons, Pinto (2005) acredita que a cultura organizacional poder ser barreira para mudanças e para a diversidade na empresa. A autora destaca algumas ações que se fazem necessárias para que a cultura seja mantida na empresa:

[...] seleção de funcionários, assegurando uma combinação apropriada na contratação de pessoas que tenham valores essencialmente compatíveis com os da organização. A administração de topo também tem um impacto importante, pois é através desta que os executivos seniores estabelecem normas que repassam a organização e por último, a socialização que é um processo de adaptação às crenças e valores da nova cultura. Quando o funcionário é admitido, a organização procura moldar seu comportamento de acordo com a cultura dominante (PINTO, 2005, p. 32).

Sabe-se da dificuldade que as pessoas têm em mudar de comportamento por iniciativa própria. Por isso, Silva (2007, p. 3) defende a importância da transmissão da cultura organizacional às pessoas.

De nada adianta fazer campanhas institucionais belíssimas, se o conteúdo da comunicação não corresponder à realidade vivida na empresa. Se os funcionários não entenderem os valores da empresa e não praticarem esses valores no diaa-dia.

\section{Estudo de caso - Caixa Econômica Federal}

A adoção da RSE não é uma mera questão de escolha, mas de sobrevivência. Diante do atual cenário, cujas partes envolvidas buscam cada vez mais respostas e atitudes que minimizem impactos no meio ambiente resultantes das atividades industriais e econômicas, a instituição estudada trabalha para modificar os modelos 
de produção até então vigentes, que garantam a produtividade da empresa com sustentabilidade.

Nesse sentido, a CAIXA iniciou seus passos na esfera ambiental operando em programas de desenvolvimento urbano e saneamento ambiental ainda na década de 80. Em seguida, a empresa aderiu ao Protocolo Verde do Governo Federal documento que estabelece as principais diretrizes para financiamento de projetos por parte das instituições oficiais de crédito.

A instituição também iniciou o financiamento de projetos pilotos para estudo e desenvolvimento de metodologia em gestão e educação ambiental. No caminho da prática responsável, a organização estudada tornou-se signatária do Pacto Global e definiu uma Política Ambiental Corporativa. Ao aderir ao Pacto Global da Organização das Nações Unidas, o banco criou o Comitê CAIXA de Política Ambiental Corporativa, uma superintendência nacional de Responsabilidade Social Empresarial e Relacionamento com Empregado, e uma gerência nacional de Meio Ambiente.

O enraizamento dos valores e princípios de RSE na cultura corporativa da CAIXA é visto pela direção atual do banco, pelos novos funcionários, consumidores, fornecedores e colaboradores, como um fator positivo.

Essa postura reflete a mudança de comportamento de um contingente considerável no relacionamento com o banco, que passa a controlar e cobrar posturas compatíveis com os conceitos e proposições preceituadas na RSE e no Desenvolvimento Sustentável.

\subsection{No caminho de uma gestão sustentável}

Com o objetivo de materializar os conceitos de RSE, a instituição em estudo adotou diversas ações para introduzir novos hábitos na rotina de seus empregados. A primeira foi a campanha "Imprima Respeito à Natureza" que, para reduzir o consumo de papel, lançou ilhas de impressão em todas as unidades administrativas. 
O resultado foi positivo. No primeiro quadrimestre de 2007, em comparação ao mesmo período de 2006, o consumo de papel sofreu redução de 7,6\%, percentual equivalente a 19,5 milhões de folhas. Essa ação gerou uma economia de R\$ 362 mil para a empresa. A quantidade de cartuchos de tonner diminuiu 10,8\%, economizando R\$1,8 milhão, como mostra o Balanço Social da CAIXA.

Outro insumo importante é a energia. Nesse sentido, o banco passou a utilizar lâmpadas econômicas e luminárias eficientes, e os sistemas de refrigeração foram substituídos por aparelhos mais econômicos.

A instituição também instalou sensores de presença para o desligamento automático das lâmpadas em instalações sanitárias da sede administrativa. Em complementação, todos os monitores de vídeo dos computadores foram configurados para entrar em modo de redução de energia após 20 minutos sem uso contínuo.

Uma campanha para melhorar o uso da água foi lançada com o nome de “Uso Racional da Água” e estabeleceu uma meta de consumo diário de 45 litros por pessoa. Para sua efetividade, os bebedouros foram substituídos por garrafões de água mineral. Isso reduziu o consumo em quase $10 \%$.

A instituição em estudo também instalou torneiras com sensores de presença para evitar o desperdício contínuo de água corrente durante a lavagem das mãos e a higienização bucal. No entanto, o banco ainda conta com unidades que usam torneiras manuais e que, muitas vezes, são esquecidas abertas.

O descarte de materiais inservíveis são insumos valiosos que agregam valor social a diversos projetos de geração de trabalho, renda e até inclusão digital de comunidades carentes. O banco destina seus microcomputadores descartados a projetos desenvolvidos por entidades sociais. Esses equipamentos foram utilizados na instalação de 166 salas de educação digital. Em 2006, foram certificados 4.935 alunos de famílias de baixa renda em curso básico de informática.

A organização também doou mais de 950 toneladas de papéis recicláveis e 4.878 unidades de cartuchos de impressoras para projetos sociais de geração 
de trabalho e renda. Outra medida foi a redução de gases poluentes, como a utilização de aparelhos de ar condicionado certificados e com alta eficiência energética.

Por fim, o banco em questão incluiu critérios de sustentabilidade nos contratos com os fornecedores. Todos os produtos de limpeza são biodegradáveis. Os veículos utilizados pela instituição seguem as regras do PROCONVE/ IBAMA, e, desde 2007, a organização faz uso de papel reciclado em peças publicitárias.

\subsection{0 endomarketing na Caixa}

Para uma empresa do porte da CAIXA, com aproximadamente 75 mil funcionários, a comunicação interna demorou a ser implementada. Somente em dezembro de 2000, por meio do Manual Normativo de Atividades Especiais, o banco passou a considerar o endomarketing um processo importante para a empresa.

Durante anos, o endomarketing e o marketing fizeram parte de diferentes áreas. Em 2001, como consequência da revisão de alguns processos administrativos, o banco criou uma única superintendência de comunicação, a Superintendência de Marketing Institucional (SUMAI).

Em seu organograma, a instituição estudada tem seis gerências subordinadas à SUMAI: a Gerência Nacional de Comunicação Interna; a Gerência Nacional de Publicidade e Propaganda; a Gerência Nacional de Comportamento e Informação de Clientes; a Gerência Nacional de Promoções, Cultura e Esportes; a Gerência Nacional de Internet e Meios Digitais; e a Assessoria de Imprensa - responsável pelas áreas de Loterias, Cultura e Comunicação Regional.

Para que a informação chegue aos funcionários da empresa, o banco utiliza alguns canais eletrônicos, como e-mail marketing, papel de parede e descanso de tela nos computadores, banner eletrônico, hotsite e easynet - que são mensagens na tela principal do terminal de autoatendimento. 
A instituição possui ainda um jornal eletrônico - o Jornal da CAIXA - criado em 2001, com a finalidade de facilitar a comunicação interna e o desenvolvimento das atividades do banco. O produto faz a cobertura diária das atividades da organização, privilegiando o factual da notícia e o tratamento de temas com caráter informativo. O Jornal é composto por dez editorias: Acordo Coletivo, Atualidades, Caixa pelo País, Cultura, Esportes, Gente de Talento, Gente de Atitude, Gestão de Pessoas, Hoje na Caixa e Opinião, além de um serviço de classificados.

É por meio do Jornal que o banco mantém seus empregados atualizados em relação às notícias da empresa de forma tempestiva e em linguagem simples. A veiculação é feita na página do Portal Intranet, sendo acessada exclusivamente por meio da rede de computadores da instituição.

Outra ferramenta de comunicação utilizada é a TV CAIXA. O veículo aborda assuntos relacionados ao trabalho, ações de reconhecimento, incentivo e registro de datas e fatos históricos da instituição. A primeira versão foi lançada em 2000 e teve aproximadamente 50 edições até 2004. No entanto, o projeto foi descontinuado e a TV CAIXA está em reformulação.

\section{Discussão dos resultados}

Com a finalidade de levantar informações para responder aos objetivos mencionados neste trabalho, fez-se necessário a utilização de entrevistas construídas a partir da experiência e conhecimento da autora deste estudo de caso.

As perguntas foram formuladas com o propósito único de coletar informações adicionais das áreas relacionadas ao tema.

A própria pesquisadora foi responsável pela elaboração das questões, que foram enviadas por e-mail, a pedido das áreas entrevistadas. As perguntas foram respondidas pelos gerentes nacionais da Gerência Nacional de Meio Ambiente GEMEA e da Gerência Nacional de Comunicação Interna - GECOM. 
O período escolhido foi entre os meses de junho e julho de 2008, mas, por problemas de contato com a Gerência Nacional de Comunicação Interna, o prazo teve de ser estendido até meados do mês de agosto do mesmo ano.

As entrevistas foram divididas em dois roteiros. O primeiro bloco de perguntas buscou identificar o envolvimento da CAIXA e de seus funcionários com ações socioambientais. $\mathrm{O}$ segundo roteiro foi estruturado em três blocos. Objetivou-se conhecer a comunicação utilizada e as ações de endomarketing desenvolvidas pelo banco.

Do ponto de vista da instituição estudada, a RSE é um projeto de caráter transversal e que ocorre de forma gradativa, razão pela qual o banco ainda está em processo de consolidação da responsabilidade socioambiental. Nesse sentido, a organização dispõe de ações recorrentes, como patrocínios socioculturais e esportivos, assim como eventos que ajudam a despertar a consciência socioambiental e a promover o exercício da cidadania.

Nos últimos meses de 2008, a CAIXA aprovou um conjunto de políticas de comunicação, marketing e patrocínio, relacionamento com fornecedores, e crédito e risco. A partir da formação de comissões, o banco em questão terá ações que possibilitem a inserção dos valores e princípios de RSE e de Desenvolvimento Sustentável.

Uma postura corporativa responsável exige novos modos de produção e de consumo. Portanto, o enraizamento de valores socioambientais deve ocorrer em longo prazo. Isso significa que o que pode parecer demorado e difícil de concretizar, uma vez concluído, torna-se parte da consciência coletiva que, no caso da CAIXA, inclui mais de 75.000 funcionários concursados, 11.000 estagiários, 10.000 prestadores de serviços, 3.000 adolescentes aprendizes, clientes e consumidores, além dos fornecedores, dos órgãos fiscalizados e dos controladores.

Essa visão sugere que quanto maior a quantidade de colaboradores conscientes da importância de um novo modo de produção e consumo, maior o controle exercido por eles nas questões socioambientais levadas a efeito pelas empresas com as quais mantêm relacionamento de negócio. 
Nessa linha de raciocínio, os impactos diretos produzidos pelas atividades do banco em questão ao meio ambiente são mínimos. Por outro lado, os indiretos são em grandes proporções, o que deixa a instituição em desvantagem em relação a empresas cujos impactos diretos são aferidos concomitantemente à atividade.

Uma informação relevante para este estudo foi constatar que os empregados da CAIXA conhecem as ações da instituição na esfera ambiental por meio do Balanço Social da empresa, divulgado anualmente com dados do exercício anterior.

Entretanto, o banco pesquisado não pode mensurar os resultados de práticas sustentáveis, recorrentes de ações de patrocínios culturais e esportivos, nem qualificar a capacitação de seus funcionários.

Apesar do processo de aprendizado e dos avanços obtidos pela CAIXA, avalia-se a importância de o banco definir seus próprios indicadores de sustentabilidade, para que a empresa tenha a dimensão de como vem atuando e, a partir dessa avaliação, mensure os resultados no âmbito socioambiental.

Vale destacar que faltam ações concretas de endomarketing para o enraizamento dos valores e princípios de RSE na cultura corporativa da organização, para que a imagem de empresa engajada nos preceitos sociais e ambientais seja consolidada efetivamente.

\section{Considerações finais}

Sabe-se que hoje a discussão da sustentabilidade é colocada de forma contundente pela sociedade. Os consumidores já atuam como stakeholders e escolhem produtos de empresas que não agridem o meio ambiente. Essa preocupação, no entanto, ainda é falha como fator determinante na escolha de uma instituição financeira. A maioria dos consumidores prefere bancos que oferecem benefícios e descontos em seus produtos mesmo que não sejam ligados a questões sociais e ambientais. 
Com base nos dados colhidos e analisados neste trabalho, pode-se constatar que é difícil mudar antigos valores de um determinado público, assim como é um desafio inserir novos hábitos e práticas na cultura corporativa de uma instituição financeira que precisa atingir metas e gerar lucros recordes todos os anos.

Para alguns autores como Almeida (2002), Becker (1997) e Merico (2002), a RSE é definida como a capacidade de se crescer economicamente em harmonia com o investimento social e a preservação ambiental. O estudo mostrou que as empresas brasileiras reconhecem o retorno de imagem e financeiro quando exploram uma postura ambientalmente correta e, para um resultado mais eficaz, elas utilizam a comunicação como instrumento na construção do relacionamento com os stakeholders, assim como na consolidação da marca no mercado brasileiro.

A partir deste estudo de caso, pode-se verificar que a CAIXA, instituição financeira pesquisada e analisada, reconhece a importância do desenvolvimento sustentável como parte do negócio. Essa mudança de comportamento foi responsável por uma nova consciência econômico-social, levando a empresa a avaliar melhor as consequências de seus investimentos para a organização, a sociedade e o meio ambiente.

A partir da análise dos canais de informação do banco em questão e o seu alcance junto aos empregados, foi possível identificar que a CAIXA possui uma comunicação pouco estruturada. O site da empresa não oferece conteúdo sobre o tema em discussão e links que redirecionam o navegador para informações de RSE. Não há um índice de consulta do histórico sustentável do banco, assim como não é possível conhecer os marcos conceituais de mudanças climáticas da instituição e aprofundar a pesquisa sobre o desenvolvimento sustentável da empresa.

Ao se compreender os valores corporativos da CAIXA, conclui-se que o desafio da sustentabilidade está na estrutura do banco. Por outro lado, a empresa precisa mudar sua cultura corporativa e seu modelo de gestão para consolidar as políticas de RSE e fortalecer a imagem de banco sustentável. Algumas iniciativas adotadas pela CAIXA, como as ilhas de impressão, o racionamento d'água, o descarte de materiais inservíveis e a economia de energia elétrica contribuem para essa mudança de hábito e para a inserção de novos valores. 
No entanto, para que isso ocorra, é essencial que os funcionários percebam que agregar sustentabilidade ao negócio é algo bom para eles, para a Instituição e para a sociedade. Se não há essa percepção, não há mudança de comportamento.

A partir dos conceitos de endomarketing defendidos por Bekin (1995), Grönroons (1993), Kempenich (1997) e Silva (2007), pode-se concluir que a comunicação interna da CAIXA é falha. Verifica-se que não há integração das gerências e incentivo a todos os funcionários, o que compromete o envolvimento com as políticas e os valores da instituição. Vale destacar que a informação não chega a todos os funcionários em sua totalidade e igualdade. Ou seja, a comunicação precisa atingir todos os empregados para que a mudança de comportamento seja integral.

Identificou-se que as ferramentas utilizadas pelo endomarketing são direcionadas aos funcionários efetivos, que recebem as informações por e-mailmarketing, papel de parede, descanso de tela, banner eletrônico, hotsite e asynet. Vale ressaltar que o corpo funcional da CAIXA também é formado por estagiários, prestadores de serviço e jovens aprendizes, e todos são parceiros e atuam como stakeholders. Logo, para se alcançar uma comunicação interna efetiva, faltam à organização em questão ações integradas que priorizem o público interno da diretoria à equipe de limpeza, antes de ampliar a sua divulgação para seus clientes e parceiros.

Durante o trabalho, ainda foi possível verificar que o Portal da CAIXA na Internet não fala de RSE, sustentabilidade ou práticas ambientais. O Jornal da CAIXA na Intranet é outra ferramenta que prioriza a cultura corporativa, destacando matérias que têm como foco principal assinaturas de convênios, visitas de autoridades, premiações de funcionários e inauguração de agências bancárias.

Não obstante aos avanços de cunho ambiental, entende-se que a organização aqui estudada enfrenta ainda alguns desafios. O principal deles é a definição de indicadores que mostrem a atuação da empresa no desenvolvimento sustentável. A definição de tais indicadores é primordial para que o enraizamento dos valores de RSE na cultura corporativa do banco seja permanentemente e pertença à consciência coletiva da instituição. 
A partir das informações coletadas na pesquisa, foi possível identificar alguns pontos que podem ser melhorados pela CAIXA e utilizados na educação e conscientização das pessoas responsáveis pelo negócio. Entende-se como extremamente importante um levantamento amostral da influência e da percepção do endomarketing junto ao corpo funcional do banco em questão.

Outro ponto identificado que pode ser melhorado é a criação de um canal interativo sobre a RSE da CAIXA. A uma instituição do porte da CAIXA impõe-se a necessidade de um banco de dados que garanta ao cidadão acesso facilitado à sua história social e econômica.

Por fim, acredita-se que o desenvolvimento de novos canais de endomarketing, ou a reformulação dos canais já existentes seja imprescindível no auxílio à estrutura e aos processos de gestão da CAIXA, contribuindo com reflexos positivos na vida de seus funcionários, clientes, investidores e fornecedores.

\section{Corporate social and environmental responsibility: a case study at caixa econômica federal}

\section{Abstract}

Increasing environmental awareness has consolidated Corporate Environmental Responsibility in the brazilian banking sector. The main public and private banks in the country began to realize that it is possible to be sustainable and have profit. Internal communication, in this case, plays a fundamental role in the disclosure of a social, environmental and economic part of these institutions so that these new values are incorporated and consolidated by their employees and eventually reached by their customers. To study the corporate values of Caixa Econômica Federal and research the communication tools used by the institution was essential to identify and understand the difficulties faced by a public bank in developing an internal communication which sensitize employees to the practice of sustainability within and outside the company. To have an awareness and attitude socio-environmental depends on rooting values into the corporate culture of the institution. 
Keywords: Corporate culture. Public bank. Internal communication. Environmental responsibility. Brazilian banking sector.

\section{Referências}

ALMEIDA, Fernando. O bom negócio da sustentabilidade. Rio de Janeiro: Nova Fronteira, 2002.

BECKER, Dinizar Fermiano. Desenvolvimento sustentável: necessidade e/ou possibilidade? Santa Cruz do Sul: EDUNISC, 1997.

BEKIN, Saul Faingaus. Conversando sobre endomarketing. São Paulo: Makron Books, 1995.

BICALHO, Aline G. D. et al. Responsabilidade social das empresas: a contribuição das universidades. São Paulo: Instituto Ethos, 2003. v. 2.

BOFF, Leonardo. Saber cuidar: ética do humano, compaixão pela terra. Petrópolis: Vozes, 1999.

CAIXA ECONÔMICA FEDERAL. [Home page]. Disponível em: <http://www. caixa.gov.br>. Acesso em: 5 mar. 2008.

FEDERAÇÃO BRASILEIRA DE BANCOS. [Home page]. Disponível em: <http:// www.febraban.org.br/p5a_52gt34++5cv8_4466+ff145afbb52ffrtg33fe36455li5411

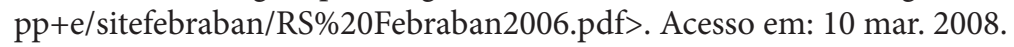

FÉLIX, Joana d'Arc Bicalho et al. Ganhos de mercado por meio do marketing ambiental. Revista Universitas de Comunicação, Brasília, v. 2, n. 1-2, p. 37-47, 2004.

GRÖNROOS, Christian. Marketing: gerenciamento e serviços, a competição por serviços na hora da verdade. Rio de Janeiro: Campus, 1993.

HENDERSON, Hazel. Além da globalização. São Paulo: Cultrix, 2003.

INSTITUTO BRASILEIRO DE DEFESA DO CONSUMIDOR (IDEC). Avaliação comparativa de responsabilidade socioambiental dos bancos no Brasil: Fev/2008. Disponível em: <http://www.idec.org.br/arquivos/RSE_bancos_RelatorioFinal. pdf>. Acesso em: 25 mar. 2008. 
INSTITUTO AKATU. Responsabilidade social das empresas: percepção do consumidor brasileiro, 2006/2007. Disponível em: <http://www.ethos.org.br/_ Uniethos/Documents/Sumario_RSE_2006_2007_Ethos_Akatu.pdf >. Acesso: 10 mar. 2008.

INSTITUTO ETHOS. Responsabilidade social empresarial: perguntas e respostas. Disponível em: <http://www.ethos.org.br/pri/princ/ prespostas/index.asp >. Acesso: 10 mar. 2008.

KEMPENICH, Mario Afonso. Marketing biruta: como (re) orientar as empresas, os negócios e a si próprio em tempos de rápidas e bruscas mudanças de mercado. Salvador: Casa da Qualidade, 1997.

MARQUES, Vânia de Lourdes. Sustentabilidade empresarial no sistema financeiro brasileiro. 2004. Dissertação (Mestrado)-Curso de Especialização em Gestão de Negócios Sustentáveis do LATEC, UFF. Campus Universitário Praia Vermelha. Disponível em: <http://66.102.1.104/scholar?hl=pt-BR\&lr=lang pt\&q=cache:YRWNlJht-gwJ:www.ebape.fgv.br/radma/doc/ GEM/GEM-014. pdf+related: YRWNlJht-gwJ: scholar. google.com>. Acesso em: 15 mar. 2008.

MARTINS, Uadson Ulisses Marques. Stakeholders e as organizações. Centro Integrado de Ensino Superior do Amazonas - CIESA. 2001. Disponível em: <http://www.fiescnet.com.br/senai/conhecimento/arquivos/anais/DraAline/ STAKEHOLDERSEASORGANIZACOES.pdf>. Acesso em: 15 mar. 2008.

MERICO, Luiz Fernando Krieger. Introdução à economia ecológica. 2. ed. Blumenau: EDIFURB, 2002.

ORGANIZAÇÃO DAS NAÇÕES UNIDAS. Conferência das Nações Unidas sobre meio ambiente e desenvolvimento: 1992, Rio de Janeiro, Agenda 21. 3. ed. Brasília: Senado Federal, 2001.

PINTO, Marta Maríci Rímoli Ajej. Cultura organizacional e características de liderança em empresas de Uberlândia e região. 2005. Dissertação (Mestrado em Psicologia)-Universidade de Uberlândia, Uberlândia, 2005. Disponível em: <http:// www.webposgrad.propp.ufu.br/ppg/producao_anexos/014_Marta\%20Marici\%20 Rimoli\%20Ajej\%20Pinto.pdf>. Acesso em: 5 maio 2008.

SILVA, Mariana Azevedo da. Endomarketing e responsabilidade social corporativa: descobrindo o diferencial competitivo. 2007. Monografia. (Especialização em Marketing e Comunicação)-Centro Universitário de Belo Horizonte, Belo Horizonte, 2007. 
